\title{
THE SUBPOLITICS OF ONLINE PIRACY A Swedish Case Study
}

\section{Jessica Linde}

Ph D Student, School of Social Sciences, Linnaeus University, Växjö, Sweden. E-mail: jessica.linde@lnu.se

\author{
Simon Lindgren
}

Professor, Department of Sociology, Umeå University, Umeå, Sweden. E-mail: simon.lindgren@soc.umu.se

\begin{abstract}
'Pirates' and 'anti-pirates' have become common concepts in the cultural political debate, as the file sharing phenomenon is a delicate and disputed subject. The fact that people organize in networks to share data with each other has led film and music companies from all over the world to initiate a number of anti-piracy organizations, assigned to protect the property rights to culture and information. In Sweden, the industrial organization The Swedish Bureau of Anti-piracy on the one side, and the network The Bureau of Piracy together with The Pirate Party, on the other, play important parts in the prevailing conflict. The purpose of this paper is to apply a sociological perspective on the collective act of file sharing. By focusing on the distinctly organized part of file sharing activities as well as on the everyday practices of users, the goal is to describe how the collective action and the production of knowledge, taking place in relation to online piracy, can be understood.
\end{abstract}

Key words: subpolitics, subactivism, social movements, cognitive praxis, file sharing, online piracy, The Bureau of Piracy, The Pirate Party, Sweden

INTRODUCTION

It is obvious that digital media have brought along social transformations that are at least as dramatic as those generated in the technological and economical arenas (Castells 1996; Luke 1989; Miles 1988; Turkle 1995). The rise of internet-based communication has contributed to the emergence of a number of new forms of cultural expression and social interaction (Jenkins 2006a; Rheingold 2002), but it has also led to previously known cultural forms being amplified or transformed (Lindgren 2007).

One example of this is the semi-novel phenomenon of file sharing of copyrighted material, which is an activity that engages internet users in networks where for example movies, music and software can be shared freely. As a rapidly growing number of people gained access to the internet during the 1990s, and as connection speeds got faster and faster, the subsequent introduction of mp3 technology along with the first widely used peer-to-peer application, Napster in 1999, had the effect of moving digital and online piracy from the underground and into the mainstream.

Since file sharing in general is a rather broad concept, including any type of sharing of any type of files, we will use the term online piracy to denominate the activity under study in this paper. As will be made clear in the following section, online piracy can be addressed in many different ways. In this paper, however, we approach the act of online piracy as an issue of participation, in terms of mobilized collective action.

In public debates, online piracy has tended to be equated with unlawfully downloading and/or uploading copyright protected music, movies and software. With the emergence of a number of pro-piracy actors however, a shift in focus has gradually taken place and - at least in Sweden - online piracy has occasionally been discussed in terms of a powerful global movement.

Although the last couple of years have seen some academic work discussing online piracy in terms of mobilized collective action (Mason 2008; Strangelove 2005), little research has applied frameworks from social movement theory on online piracy. We aim to make a contribution to previous research within this field by combining Beck's (1997) concept of subpolitics, Bakardjieva's (2009) idea of subactivism and Eyerman and Jamison's (1991; 1998; 2005) theoretical framework for analyzing social movements as cognitive praxis. While the term social movement is sometimes used to refer to any type of collective action, we will employ it in a stricter sense. According to the definition that we use, it is reasonable to apply the term when a group of people is acting together to change society in some way and when this collective action is grounded in some kind of societal conflict (Eyerman \& Jamison 1998).

The aim of this paper is to contribute to a discussion of potential changes in forms of political activism, especially among young people. Our starting point is the question of whether parts of the collective act of online piracy can be recognized as a social movement. By focusing on the distinctly organized part of the movement as well as on the everyday practice of online piracy activities among casual users, our aim is to analyze the forms of collective action and the production of knowledge taking place within this potential movement, and to discuss how these processes can be understood.

Our analyses are based on document analysis and qualitative interviews with young people within the organized part of the movement as well as those simply engaged in the everyday practice of online piracy. The study was carried out in a Swedish context. As will be further elaborated later in this text, online piracy in Sweden serves as an interesting case.

\section{APPROACHING ONLINE PIRACY}

From an academic point of view, online piracy can be addressed in a multitude of ways. One could apply a purely technological perspective to map infrastructure, channels, protocols, hardware, or whatever else is of interest in order to understand how online piracy is practically 
carried out (Gummadi m.fl. 2003; Ripeanu \& Foster 2002). But there are also legal and economic perspectives on the subject. These have been emphasized by scholars focusing on normative changes, shifts in people's sense of justice or the economic effects of online piracy on the cultural industries (Bowrey 2005; Gordon 2005; Hinduja 2006; Murray 2003; Oberholzer-Gee \& Strumpf 2007; Schmidt 2007). Yar (2005, p. 691) writes, on the concept of piracy that "the term ought to be viewed not simply as a piece of legal terminology, but also as a rhetorical device which, by evoking associations with bloodthirsty seafaring brigands, is used to moralize copyright infringement as a 'serious crime'".

Even though there are legal peer-to-peer networks (Wright 2008), and in spite of the fact that there are farreaching differences of opinion as regards whether even the dissemination of copyrighted files is an ethical violation at all (Bowrey 2005, pp. 127-169; Gantz \& Rochester 2005, pp. 27-61; Hinduja 2003; Strangelove 2005, pp. 79-98), the question of whether to engage in online piracy or not tends to be framed mainly as being of ethical and legal character (Gupta m.fl. 2004; Swinyard m.fl. 1990). While some researchers have claimed the sharing of pirated files to be an issue that lacks moral intensity - that is: it tends to feel less serious than many other ethically conditioned behaviors, such as theft of material property (Logsdon m.fl. 1994) - others have stated that digital technologies have a distancing effect leaving the users feeling free of personal involvement and responsibility for their actions (Summers \& Markusen 1992).

Yet another perspective is of a more philosophical character and concentrates on issues regarding everyone's right to culture and information (Söderberg 2008; Vaidhyanathan 2004). One can also claim that the issue is largely political and that it can be interpreted in terms of collective action, as a form of cyber activism where commercial and capitalist powers are resisted (Lunney 2001; Strangelove 2005). Accordingly, some writers have described the culture of online piracy as a strongly structured and oppositional social force (Cooper \& Harrison 2001; McLeod 2005; Sum 2003) with the potential to re-shape the very basis of the cultural economy by annihilating intellectual ownership (Fattah 2002; Giesler \& Pohlmann 2003; Leyshon m.fl. 2005).

All of the above perspectives are important in understanding online piracy as a whole. They are, of course, rarely as delineated and separated in practice, but in this paper we focus mainly on the political side of the phenomenon. Particularly on analyzing online pirate activities in terms of subpolitical practice and collective action.

Subpolitics and Subactivism

The type of politics which is expressed outside of the established and traditional system - often in relation to specific issues rather than to complete ideological packages - is labeled subpolitics by Beck (1997). His point is that, instead of suggesting that politics and morality are on the wane in the postmodern world, one can just as well argue that such claims are actually the result of a misconception of current social reality. The fact that many people have a declining interest in traditional formal politics should not necessarily be interpreted as an indicator that there is an actual lack of political orientation or action in society at large. This point is illustrated for example by the occurrence of activities such as culture jamming and adbusting (Klein 2000; Wettergren 2005), online campaign organizations (e.g. avaaz.org), and hacktivism (McCaughey \& Ayers 2003).

The concept of subpolitics refers to the ways in which individual, small-scale, decisions achieve political significance either because they have a direct political frame of reference, or simply because of their aggregation. And the internet has a particularly strong potential for channeling the actions of huge numbers of individual users into something larger. But the potential movements of the internet are by nature more abstract than traditional social movements - at least at first glance - since they appear as relatively fragmented systems of joint action: someone in rural Sweden downloads a file uploaded by an internet user in Sydney. That same file is then shared with an individual in Amsterdam. There is no obvious chief ideologist or leader, these three people have never met, and they all have their individual motivations for downloading the file (one of them simply might not care, the second may be active writing essays on the obsolescence of copyright, the third might just be desperately looking for a specific song or movie). The consequence of their - in practice - collective action is none the less potentially political. This idea will be further elaborated in our analysis.

Beck writes that we must avoid looking for politics in the wrong places - in political parties, parliamentary debates or elections. In today's world, politics are emerging from new places. We argue in this paper that online piracy can be seen as a subpolitical practice - as a form of politics emerging from such new places.

At the same time, online piracy can be understood as subactivism. Bakardjieva (2009, p. 96) argues that "as much as Beck emphasizes forms and manifestations of politics located underneath the surface of formal institutions, his construct retains a strong public and activist element". She introduces the idea of subactivism as a third level of citizen participation, the first being a level of formal institutional politics and the second represented by Beck's concept of subpolitics. Subactivism is, more so than subpolitics, located in the "private sphere or the small social world" (ibid). It relates to personal empowerment more than political power in a strict sense. Personal empowerment is here seen as "the power of the subject to be the person that they want to be in accordance with his or her reflexively chosen moral and political standards" (ibid).

Subactivism arises spontaneously, for example in the form of new dimensions of work, homemaking, parenting or entertainment. It "may or may not leak out of the small social world and become publicly visible" (ibid). As we will show later on, Bakardjieva's idea of subactivism can deepen the understanding of online piracy as political participation. Especially when related to what we will describe as different online piracy cultures. Bakardjieva's argument that there is an ever present potential for subactivism to be mobilized by trigger events and transformed into overt public activism, is of particular relevance to our analysis of the development of the online piracy movement in Sweden. The movement, we will argue, is conspicuously fragmented and ideologically differentiated and characterized by individualism and subactivism.

In sum, online piracy can be perceived in terms of subpolitics and/or subactivism. But our theoretical question still remains: If we are to recognize online piracy as a social movement in a more conscious and ideologically motivated sense, what fundamental ideas and interests is it characterized by? How can the cognitive praxis of the movement be described? 
Social Movements as Cognitive Praxis In discussing online piracy in social movement terms we have been guided by Eyerman and Jamison's contextually based theoretical framework on social movements as cognitive praxis $(1991 ; 1998 ; 2005)$. Studies of social movements and social change stem from different scientific paradigms and perspectives. Eyerman and Jamison's approach can be understood as embedded in the European identity paradigm, focusing on aspects of the broader context of movements, the creation of collective identity related to societal conflicts and symbolic action (Eyerman \& Jamison 2005). ${ }^{1}$

Eyerman and Jamison's concept of cognitive praxis has helped us analyze this movement as a process rather than a product. The framework refers to the process of forming unity within a movement through the generation and dissemination of certain ideas and knowledge. According to Eyerman and Jamison (2005), one can avoid converting the cognitive praxis, or core identity, of a movement into solely ideological positions or organizational programs by understanding movements as producers of knowledge and cultural transformations. Furthermore, focusing on movements as cognitive actors is one way of avoiding the polarization between grand theory and particularism that characterizes many studies on social movements, where the controversies revolve around the ambition to speak about virtually every social movement or one movement in particular.

Cognitive praxis consists of three dimensions, which are said to be of vital importance to the existence of any movement. In this paper we will analyze online piracy from the perspective of these dimensions. Firstly, Eyerman and Jamison write about the cosmological dimension, that is, the utopian messages that the movement stands for, what needs to be "overcome or transcended" (1998, p. 167). Secondly, they introduce the technological dimension, which revolves around the performance techniques of activists as cultural producers. Thirdly, they discern an organizational dimension, reflected in the movement's ideas of how to encourage active participation and balance between 'the leaders and the led'. A movement consists of individual members and what Eyerman and Jamison refer to as movement intellectuals and movement artists. Since movement intellectuals are more visible than individual members, not the least in the media, they are important actors in conveying the cognitive praxis.

Together, these three dimensions make up the cognitive praxis which, according to Eyerman and Jamison, is constantly performed in any social movement. However, this does not mean that the cognitive praxis is explicit or obvious, even to the activists themselves. Rather, the three dimensions need to be identified by someone consciously looking for them. This will be our task in the following, and in line with Eyerman and Jamison's ideas, we have employed these dimensions as analytical themes that have served as tools for navigating the data.

In the field of social movement studies, the presentday forms of political activism have been much debated. The so-called new social movements of the late 1960's (Melucci 1998) differed from traditional movement such as the workers' and socialist movements in many ways. These new, or second wave, movements were concerned

1 This approach differs from for example the American resource mobilization perspective where social movements are rather described in terms of rational collective action with the purpose of bringing about social change. At focus here are for example forms of organization, strategies for action and the creation of social networks. with "issues such as women's right, gender relations, environmental protection, ethnicity and migration, peace and international solidarity - with a strong (new) middleclass basis and a clear differentiation from the models of working-class or nationalist collective action that had historically preceded them" (della Porta \& Dani 2006 , p. vii). The distinction made between the first and the second wave is mainly based on a shift from class conflict to issues of identity. Since much has happened since the 1960's when these new social movements emerged, one might ask whether it is possible to distinguish specific features characterizing a third wave of social movements. In the field, issues of globalization and new spaces for political participation are being explored in relation to the study of social movements. Eyerman and Jamison, however, argue that the new forms of political activism seen today, for example in protest actions regarding animal rights or anti-globalization, have not yet achieved the status, character or cultural significance that is distinctive for earlier movements. They argue that the construction of an imagined opponent - an Other - is too vague, that the actions and forms of protest are remains from earlier movements, not adapted to the new issues and that the support from the public is too weak.

The lack of support can be related to Bakardjieva's notion of subactivism. Her ambition is to challenge two common approaches concerning the internet's potential for political participation, one being the liberal individualistic idea of "direct democracy via electronic means" $(2009$, p. 91) and the other being communitarian versions of democracy emphasizing for example community-building and community-maintenance. She discusses Dahlgren's (2007) notion of how the internet, rather than "offering new and more inclusive fora for public deliberation" facilitates "counter-publics" (ibid) created by groups and interests that are not represented in the mainstream public discourses. Examples given of such counter-publics are the Zapatistas movement and, in comparison with Eyerman och Jamison's discussion above, the anti-globalization movement.

What is particularly interesting when relating these discussions to online piracy is that the public support can hardly be described as weak, in the same sense as issues of animal rights or antiglobalization. In Sweden 18 percent of the population engages in online piracy activities, and as for the age group 16-25 years about 50 percent (Findahl 2009).

We hope to make a contribution to these discussions by combining the notions of subpolitics, subactivism and cognitive praxis. Departing from these theoretical frameworks we will suggest that it can be fruitful to describe parts of online piracy activities in social movement terms. We will argue that the cognitive praxis is ideologically diffuse, fragmented and 'vague', and this is a point where we agree with Eyerman and Jamison in their discussion of new forms of political participation. However, we will suggest that this can be incorporated in the cognitive praxis of this movement, rather than to disclaim the existence of social movements today. As for Eyerman and Jamison's argument that the forms of political actions are not adapted to the issues of protest today, we will argue the contrary.

We now turn to the Swedish case of online piracy on which we base our analysis.

THE CASE

Social movements are related to particular spaces in time, and to lived conflicts, dilemmas or problems that are specific to the contexts out of which they spring. Hence, 
before proceeding with the dimensions of cognitive praxis in the Swedish online piracy movement, it is appropriate to say a few things about the context from which this movement originates.

The Swedish Context The case of the emergence of an online piracy movement in Sweden is particularly interesting when focusing on the activity in terms of movements as cognitive praxis. Sweden is known as the home country of several movement actors and internationally recognized representatives of the propiracy perspective such as The Bureau of Piracy (Piratbyrån, from now on TBP) and The Pirate Party (Piratpartiet, from now on PP). PP is a Swedish political party, which was founded in 2006 and has inspired the creation of similar parties in several other countries. As for representation in the Swedish Parliament, the party did not capture enough votes to get a mandate in the recent Swedish general election 2006, the same year as the birth of $P P$. However, $P P$ received much attention inside as well as outside of Sweden for getting one mandate in the European Parliament in 2009.

$T B P$ is an organization working since 2003 in Sweden to support people who are in opposition to current rules and ideas relating to copyright and intellectual property (Rydell \& Sundberg 2009). The organization is related to The Pirate Bay - allegedly the largest BitTorren site of its kind in the world, now famous for the much medialized 2009 court case against the people behind it The Pirate Bay was originally created by members of TBP but later became independently operated. $P P$, however was never directly affiliated with neither TBP nor The Pirate Bay. Not until May 2010, that is. What happened then was that $P P$ decided to take over the delivery of bandwidth to The Pirate Bay since it was shut down by a German court. The press release stated that "[w]hen other politicians assign investigations and avoid being held accountable, says Rick Falkvinge, PP takes responsibility and acts with own resources for the nation's security of information and constitutive freedom of speech. We are now The Pirate Bay's Internet Service Provider" (PP's website).

In the early autumn of 2003 a couple of young Swedes launched a press release stating the birth of TBP. The choice of name was a humoristic comment to the name of a Swedish pro-copyright group - The Swedish Bureau of Anti-Piracy (Svenska Antipiratbyrån) - an organization representing a number of film companies since 2001. In one of our interviews ${ }^{2}$ a founder of TBP, Magnus Eriksson ${ }^{3}$ (25 years old, student in cultural sciences) elaborates on their choice of name:

There was no Bureau of Piracy for them to be against. They were against an invisible mass. So we thought that "ok, you can be against $u s^{\prime \prime}$. This is what we like and we think this is a good thing. Now they had to be against someone that gave them counter arguments. This made it trickier.

This was an important step in the process of identity formation for the online piracy movement in Sweden. Online piracy was not a new phenomenon. On the contrary, it was, as argued in $T B P^{\prime} s$ press release, "already a powerful movement where millions of people create free

\footnotetext{
2 Metodhological aspects will be further described in the next section. A quote from one of the interviews is used here only to help illustrate the context.

3 High-profile movement intellectuals are presented with their actual name throughout the text.
}

access to culture". However, there was no given place for this "invisible mass" in the media dramaturgy (Rydell \& Sundberg 2009). With TBP the movement was beginning to form a voice and an identity, especially in the media and the public debate, now mediated by a couple of new-born movement intellectuals. One could also argue that the founding of $T B P$ was a fundamental step in the process of turning individual opinions and concerns into "various forms of political and social participation" (della Porta \& Diani 2006, p. 3). What happens in this process is that "[m]oral and philosophical worldviews and deeply felt convictions are then paralleled by specific attempts by individuals to stop threatening developments, redress instances of injustice, promote alternative options to the managing of social life and economic activity" (ibid). In other words, this is a process of transforming private troubles into public issues, a fundamental process for every social movement (Eyerman \& Jamison 2005).

One of the goals emphasized in the press release was "to start a debate about copyright as a political issue". Almost seven years later the issue indeed has to be described as politicized. $P P$ is the obvious example, and while this small political party is not represented in the Swedish Parliament, they did - as mentioned - manage to get one mandate in the EU election in 2009. This forced all of the other political parties represented in the Swedish Parliament to consider the question of online piracy, or at least to recognize it as an important issue for a generation of young voters. The fact that all of the youth wings of the Swedish political parties in different ways have made the question of online piracy part of their political agendas indicates a generational divide concerning the political understanding of these issues.

One could easily say that $T B P$ successfully paved the way for getting the issue of copyright noticed as a political one. However, we suggest that the politicization of these issues needs to be further contextualized. Since we are trying to delineate the Swedish context, other important mechanisms have to be taken into account, for example two legal aspects. A few months before the EU election in 2009, the so called IPRED-law came into force in Sweden. IPRED stands for Intellectual Property Rights Enforcement Directive and is an EU-directive. Very briefly, it gives a copyright holder the right to request information about a user's IP address, something that created strong reactions within the online piracy movement as well as outside of it, and the law was described by many as a violation of privacy. The reactions can in turn be understood in the light of the implementation of the Swedish FRA-law earlier the same year. This law was also widely debated in terms of violation of privacy since it meant that the National Defence Radio Establishment in Sweden was given the right to conduct signals intelligence on all wire-based communication over Swedish borders. Drawing on this, we further suggest that what was noticed as political was particularly issues of privacy, integrity, freedom of speech and state surveillance, perhaps more so than the issue of copyright emphasized by the TBP.

However, one crucial aspect here was that copyright as a political issue had undergone a fast transformation from an abstract philosophical issue to a concrete private one. We argue that in this process some key factors were, among others, the legal changes and the formation of a cognitive praxis and a movement identity expressed by movement actors like $T B P$ and $P P$. These key factors can also be understood as trigger events in relation to a substantial base of subactivism.

Why the online piracy movement has been so successfully established in Sweden is an interesting 
question. Sweden is sometimes described as a leading nation when it comes to information- and communication technologies, with high levels of computer access and a well-developed broadband infrastructure. This could be one possible explanation among many others. Another one could be the fact that Sweden has a solid tradition of strong popular movements. According to Eyerman and Jamison's analysis of the Swedish progressive music movement in the 1970's one significant and unique aspect was that "the Swedish music movement gave rise to an integrative cognitive praxis, through which a vision of a 'non-commercial' music, with a do-it-yourself, participatory flavor, was given a coherent organizational and ideological structure" (1998, p. 144). Although interesting, the question of why the Swedish online piracy movement has been so successful is not the main topic of this paper. Nonetheless, we can note that the online piracy movement originating from this Swedish context makes an especially interesting case for a study of cognitive praxis.

Analyzing Cognitive Praxis When researching social movements there is always a need to balance issues of empathy versus reluctance towards the object of study. On one level, the researcher must identify with the analyzed movement - and researchers of social movements often risk assuming roles of reformers or ideologists. In some ways, it is inevitable that you become an intellectual of the movement to a smaller or larger degree. But at another level, the researcher must strive to maintain impartial neutrality and thereby risking assuming an overly skeptical position. We have been guided by Eyerman and Jamison's (1991) idea of harmonizing qualified subjectivity with a critical distance. Furthermore, our perspective is highly exploratory and we have tried to keep our focus on the overarching question and the theoretical perspective when approaching the data.

Our analysis has been shaped by our theoretical frame of reference. In parallel with collecting and analyzing the data, we have had an ongoing discussion about how the cognitive praxis of online piracy could be assessed in the best way. A movement can be read in many ways and cognitive praxis can be empirically studied and mapped through interviews with both movement representatives and loosely tied members as well as through official documents and other texts relating to the movement in question. This insight was present early in our methodological reflections and constituted an important reason for the varying approaches of collecting data, soon to be described. The arguments made in this paper stem from a couple of various empirical touchdowns, made at different occasions and focusing on different aspects of how to interpret a social movement's cognitive praxis.

A first set of data was collected for a field study carried out at Växjö University, Sweden, by the end of 2005 (Linde 2005). This study focused primarily on TBP, and the empirical material was gathered through interviews with two founding members of $T B P$, also active as movement intellectuals within the organization. The interviews were of a semi-open character, with certain key themes relating to the dimensions of cognitive praxis being dealt with. This first set of data collection also included material from TBP's website and forum, both important and basic tools for the activities of the organization, as they represent key channels for expressing the ideas and interests of $T B P$. The book Copy Me - Collected texts from The Bureau of Piracy (Kaarto \& Fleischer 2005) which was published by representatives of TBP also served as an important source of information. This book can be seen as an extension and partial documentation of texts from the website. The material for this field study also included a set of $T B P$ media appearances; in particular two episodes of a Swedish television debate show in which representatives of TBP appeared. The first episode was from 2003, the same year that $T B P$ was founded and the second episode was from 2005. The interviews with representatives of $T B P$ and readings of the website and forum can both be seen as cases of 'the movement in movement', where the TBP book instead serves as an expression of the movement's ideas made public on its own terms, and where readings of $T B P$ in the media can be understood as an expression of how the movement formulates itself through movement intellectuals and how they make their ideas public in direct dialogue with other actors. Since what Eyerman and Jamison refer to as movement artists can be important actors in the expression of the cognitive praxis in a movement this first set of data collection also included interviews with cultural producers associated with the online piracy movement. ${ }^{4}$

In this paper we also make use of a second set of data, originally collected in 2009 within a research project on the moral dimensions of online piracy carried out at Umeå University and previously presented in an edited volume on youth cultures (Lindgren 2009). For this study, interviews with around 10 young people moderately to highly engaged in online piracy activities were conducted. The purpose of including this material in the present paper has been to identify different cultures in relation to online piracy and by doing so, expand on the idea of online piracy in terms of mobilized collective action and social movement.

In practice, we often switched back and forth between analyzing interviews, on- and offline texts, the $T B P$ web forum etc. Issues that were raised when working with one type of material made us return with new questions to previously analyzed material, etc. All in all, these two sets of data gives us a solid base for discussing the Swedish online piracy movement as cognitive praxis as well as the formation process between 2003 and 2010. The empirical material also gives us an opportunity to problematize the notion of an online piracy movement as such.

ONLINE PIRACY AS COGNITIVE PRAXIS

We will begin our exploration with an analysis of different online piracy cultures. After this we turn to the cognitive praxis of the movement. Firstly, the organizational dimension, where we also discuss movement intellectuals and movement artists. Secondly, the technological dimension, and thirdly the cosmological dimension.

Online Piracy Cultures Online pirate culture is built upon the collective engagement of a large number of people. As Vaidhyanathan $(2004$, p. 21) states, the most remarkable thing is not that millions of individuals from all over the world are downloading a vast number of files, but rather that large numbers of people around the globe are actually making an effort - cracking, sorting, copying, hosting and distributing data. In approaching online piracy as a social

${ }^{4}$ TBP has a section in their website called The Artist of the Month where artists are presented and interviewed about their perspectives on cultural production and copyright. The Swedish reggae and hip-hop band Svenska Akademien (The Swedish Academy), was chosen from this list and interviewed. 
movement one fruitful place to start is discussing who and what should be considered part of this movement.

As we have touched upon earlier, there are many different arguments and motivations for downloading and/or uploading music, movies and software. Is each individual taking part in this activity to be considered a member of a specific social movement and by being so, to incorporate a distinct collective identity? Since the activity of online piracy is extending across the world, including many different countries and contexts, is the movement to be described as a global one - as sometimes stated in the public debate? We argue here that the answer to both of these questions is no.

Drawing on interviews with young people engaged in the act of online piracy we have identified three ideal typical forms of online piracy cultures; online piracy as everyday culture, political culture and innovation culture (Lindgren 2009). Although not this separated in practice, we will begin our analysis of the online piracy movement as cognitive praxis with a brief introduction to each of these cultures. This will help us nuance the notion of the large and differentiated group of people engaging in online piracy activities as homogenous, a notion visible in the description of the 'file sharer' as a subcultural hacker with a criminal identity or as a politically aware intellectual with explicit ideas about free access to culture and information.

From our interviews, it becomes clear that for many of these young people, online piracy activities are not associated with neither political dimensions, nor legal ones. Online piracy as everyday culture seems to build upon a behavior taken for granted and made possible by technology that is an integral part of their everyday lives. This part of everyday life is, for some of the people interviewed, not necessarily associated with moral aspects. Johannes (22 years old) says: “No, I don't even think about that. That it would be criminal. I've been doing file sharing for so long that I have never really thought about it that way".

As for the political aspects of online piracy, we where occasionally met with skepticism. Johannes again, when told that some argue that individual actions taken together under some circumstances can be described as political:

No, I wouldn't agree with that. I think it's much more about the fact that it's easy. I guess people are greedy in some ways, and if there's an easy way to get it, you try. And when the risk of getting caught is minimal... like... no, I can't agree with that.

Another example, a quote from Johan, 20 years old, although a bit more ambivalent, also illustrates this.

Interviewer: Can online piracy be a political action to you? Johan: [pause]... Yes... maybe... [pause]. But most of all it's a question of access, of comfort.

Interviewer: Some people see online piracy as part of a political project, for example as an anti-capitalist action... Johan: No, that's not the case. Certainly not.

People engaged in online piracy as unreflected everyday practice, as one way among other to consume culture, are neither directly affiliated with a social movement of any kind nor exercising self-perceived subpolitical action. Yet, they are sometimes used as a rhetorical device within the movement. For example as, in TBP's press release, "a powerful movement where millions of people create free access to culture".
Interviewer: If, for example, a large number of individuals are sharing files, but only, like, five percent are what one could call politically aware, would you still think that the number of file sharing activities taken together could be seen as political? That for example $P P$ could argue that:"Look! All of these people file sharing want a new society like we do!"

Johan: No... no, I don't think so. This is, I think, putting words into somebody else's mouth..

Interviewer: Yes..

Johan: From my own perspective... If I were to be used like that I wouldn't think it was ok.

Johannes and Johan are used here to illustrate an approach where online piracy is decoupled by its actors from political aspects as well as legal and moral ones. For them, piracy reflects a way to consume culture and media content that in some ways is taken for granted by a generation of young people. Online piracy as everyday culture is closely connected to Rojek's (2005) description of piracy as a new form of leisure activity for young people. He argues that these activities can be interpreted as parts of a new globalized leisure culture leading to increased social inclusion, a strengthening of youth participation in culture and society and as something that raises important issues of justice. Seen from this perspective one could argue that there are potential political aspects even where such an idea is rejected, and this is also closely connected to Bakardjievas notion of subactivism. However, we now turn to an online piracy culture explicitly described as political.

As we have touched upon earlier, online piracy can be made political in many different ways. Seen from a traditional political left-right scale it is for example ambiguous due to the fact that all of the youth wings of the political parties represented in the Swedish Parliament in different ways have made the question part of their political agendas. Our interviews do not include anyone clearly sympathizing with $P P$. Instead, our informants express a left-oriented rhetoric that can be seen as a contrast to PP's more neoliberal arguments about "civic rights", "safeguarding the privacy of the individual" and about how "monopolies are harmful to society" ( $P P^{\prime} s$ website). One of our informants, Arvid (22 years old), emphasizes the solidarity that some of the private torrent trackers ${ }^{5}$ are built upon:

Active participation in the community is rewarded, and I think that's great. It adds a whole new level to the downloading as well [...]. I don't like open trackers at all, it's like: a hundred people are exploiting ten people. Ten people that very faithfully keep their computer on, expose themselves to the risks and all that. And then a hundred people just exploiting that and giving nothing back apart from the little time that they upload, I think that's fucking crap.

Another example of how things may be articulated when online piracy is described in subpolitical terms is given by Robert (19 years old):

Interviewer: Do you think of your file sharing as something else than ordinary media consumption?

5 In open torrent trackers, such as The Pirate Bay, it is often accepted that someone downloading a file uploades data only during the time for downloading. In private torrent trackers, however, often requires that one shares a certain amount of data, for example twice as much as one downloads. 
Robert: Absolutely! In my daily life I have, like, the opinion that consumption is something disgusting that you should stay away from. I have set principles for my life, among other things that you shouldn't help those large companies who abuse this earth, and that everyone must stop consuming or else we will perish. And the same goes for... even if I would maybe wanna go to the movies, and I can afford going to the movies, I consider it a wrong thing to do. Because then money will go to companies that I don't wish to support. So then I download instead, as a pure act of resistance, so to speak. [...] For me, file sharing is a way to exist in society without being forced into this consumption that I wish to avoid.

Interviewer: Can you understand that it can be a criminal act?

Robert: Yes, of course. It is, isn't it?

Interviewer: But you don't think that's right?

Robert: No, no, no [laughing].

The third theme which appeared in the interviews - online piracy as innovation culture - is also built upon the idea of online piracy as a movement supported by enthusiasts, but with an interest in technology rather than politics as a driving force. Online piracy as innovation culture is in our interviews for example related to "a small, small group of people that are very technically motivated", so called members of the scene, or "those driving the rest of the movement forward" (Magnus, 21 years). This small group of people is developing ever more sophisticated ways to circumvent current regulatory frameworks and to find more effective file formats and ways of distribution. An interesting aspect is that it was people from such a small group, namely some key users on a Swedish IRC channel, that founded TBP in 2003. This was a meeting place for both hackers and activists that discussed issues of programming as well as continental philosophy and gathered around different projects (Rydell \& Sundberg 2009).

This brings us back to our Swedish case under study here. We have already shown how the online piracy movement in Sweden is located in a context with specific features. This is strongly related to the latter of the two questions that we have the ambition of addressing in the present section, the question of a global movement. It seems likely that there would be connections between different initiatives and movement actors over the world. The fact that the founding of $T B P$ as well as the success of $P P$ has triggered similar initiatives in other countries is an example of this. However, in spite of the cross-national potential of the technology and online piracy networks, we will - in line with Eyerman and Jamison's theoretical framework - base our analysis in a more local context.

In sum, identifying that there are different online piracy cultures helps us nuance the notion of a homogenous group of people sharing some kind of distinct collective identity. As we have shown, the gap between these different cultures can be large and even the online piracy culture that can be described as political is internally fragmented and ideologically diffuse. However, this diversity can actually be incorporated as a basis for the cognitive praxis of the movement. In the following we will argue that cognitive praxis and collective identity can indeed be found among online pirates despite the heterogeneity that characterizes even the politically organized part of the movement. Movement actors such as $T B P$ are for example consciously handling this kind of fragmentation and differentiation, which is of interest when discussing social movements of today and potential changes in young people's political activism.
The Organizational Dimension, Movement Intellectuals and Movement Artists

The question of how some of the movement intellectuals within the online piracy movement are handling the issue of conveying a collective identity departing from such a fragmented base brings us to the first dimension of cognitive praxis - the organizational dimension.

One prominent characteristic of the movement intellectuals is, on the one hand, their reluctance to talk of any common visions or ideologies, and, on the other, the need to do so. This is visible for example in our interviews with two of the founders of TBP, in TBP's book and in their media appearances. It is often emphasized that the body of members is highly heterogeneous, and there is generally a widespread unwillingness to use concepts such as "collective identity".

On the one hand, there is a wish to make rhetorical use of the fact that online piracy is a common practice. To use statistics on how many people engage in online piracy activities is an obvious way to state the legitimacy of the practice. This is occasionally done for example by $P P$ and doing so is also a way to indicate support for its own cause. Another example comes from one of $T B P^{\prime} s$ first media appearences in 2003. TBP was represented by Rasmus Fleischer (24 years old) and he argued that "there are already millions of people today creating free access, to music and so on, on the net and no one has really pled the cause of this informal movement of many millions".

On the other hand, in our interviews with TBP representatives in 2005 they carefully emphasized that they are not at all representing this large and heterogeneous movement. Still, we argue that without some kind of collective identity or cognitive praxis there would probably be no organized part or movement at all. We suggest that this highlighting of heterogeneity can itself be interpreted in terms of cognitive praxis. The intellectuals of this movement have to balance between conveying a unified cognitive praxis as a way to exist as something larger than isolated individual arguments and actions and emphasizing heterogeneity to include different online piracy cultures, motivations and interests. One interesting aspect is the way in which TBP uses this complexity to convey the cosmological dimensions of cognitive praxis. TBP's book from 2005 illustrates this well: " $[\mathrm{t}]$ he perspectives that appears are both the hacker's, the artist's, the philosopher's and the ordinary file sharer's [...] From Public Enemy to Friedrich Hayek, from the history of video games to Michel Foucault, from computer networks to pharmaceutical manufacturers".

The book is a fragmented collection of different texts such as for example interviews with movement intellectuals and artists, The Pirate Bay's public mockings of legal threats from different large companies, and philosophical texts relating to issues of culture and copyright. The foreword, written by Rasmus Fleischer and Marcus Kaarto, states that:

We are happy to live in such exiting times, to be the swarm of insects feasting on the remains of the copyright industry, while creating the future approach to technology and culture. But since this is about our lives, lives that furthermore are very different from each other, the discussion about the future can't begin in some abstract patent solution. That is the mistake that put us in this situation in the first place. And the situations are very different for an American programmer, a Swedish artist, a Namibian with AIDS, a Kurdish Santoor player, a French hiphop DJ and a Thai farmer. 
These excerpts from TBP's book involve a few cosmological aspects. We will return to them shortly. Of interest when discussing the organizational dimension is how the heterogeneity of the loosely composited movement is handled and, at the same time, actually used to broaden the issue of online piracy.

The role as an intellectual of this movement is characterized by complexity and ambivalence. Is this to be perceived as something new? It could be interpreted as a reflection of a shift from the collective to the individual domain. This shift is something we will elaborate further on, since it is prominent in other dimensions of cognitive praxis as well. However, one could also argue that the ambivalence of conveying common ideas while representing many different people is not new. It has been present in earlier social movements as well. Eyerman and Jamison illustrate this with an example of the movement artists in the new social movements of the 1960's. They argue that the cognitive praxis of a movement can have great significance for popular cultural transformation, especially through artists attributed the roles of movement intellectuals. Cultural producers and artists affiliated with a social movement become symbols of what the movement stand for. This does not mean that artists attributed the role of movement intellectual necessarily embrace it. For example, Bob Dylan many times rejected the role as movement artist although closely affiliated with the movements of the 1960's (Eyerman and Jamison 1998). In our material, two different approaches can be identified regarding movement artists, here illustrated by the interviewed Swedish band Svenska Akademien and by Dennis Lyxzén, a Swedish singer/songwriter affiliated with hardcore and punk bands such as Refused and The (International) Noice Conspiracy. Dennis Lyxzén becomes a part of our empirical material through his participation in the Swedish debate programme from 2003, together with TBP. Since Svenska Akademien is affiliated with the online piracy movement through their texts and actions, for example making their albums available for free on their website, Lyxzén can be described as a more active and 'conscious' movement intellectual. As Svenska Akademien dismisses the role of movement artists and speaks of the online piracy movement in terms of 'them', Lyxzén instead speaks of it in terms of 'us'. One could of course argue that, as for conveying and representing cognitive praxis and the role as 'spokesperson', there is a difference between artists attributed a connection to the movement, such as Svenska Akademien and Lyxzén, and self-appointed movement intellectuals, such as representatives from TBP. In our exposition here, however, we have had the ambition to show how issues of complexity regarding the role as movement intellectual not necessarily needs to be perceived as something genuinely new. Our discussion indicates that questions of representing and conveying cognitive praxis among movement artists are an issue in a new social movement as well in the movements of the 1960's.

The organizational dimension also relates to how the dissemination of knowledge and ideas is handled within a movement, how people are engaged and potential new activists recruited. As for the online piracy movement the heterogeneity of the many people engaging in the activity once again becomes clear. Potential new activists might for example be found in the sphere of subactivism and everyday culture. In this process the technology and its community-building potential plays an important part. Magnus from TBP describes a vision of how file sharers that are not initially politically inclined can experience an awakening as they become aware of the message of TBP:
Many people may come to our website, maybe in search of the answer to a rather technological question. Like, how to do this or that. And hopefully, with the help of our huge forum and all the texts that are there, this individual will realize that "Aha! It's not only about free mp3's, it is also about medicines" and so on.

In the case of $T B P$, the open forms of communication, enabled by online forums and chats, are instrumental to the organization and mobilization. Another of the interviewed representatives of TBP, Johan Allgoth (26 years old and a philosophy student), said: "It's an amazing tool! As soon as anything happens, everyone is gathered. And we can act extremely fast. And even if someone shouldn't be there, you still never miss out on anything."

Related to the organizational dimension of the cognitive praxis is also a firm belief that the creativity and competence of the individual will flourish if only the right conditions are provided for him or her to do so. As we will discuss in the next section, technology can be important here as well. When new knowledge is needed, the organization often turns to the "collective intelligence" (Lévy 1999) of the forums, or to chats. This focus on participatory and open forms of communication, together with the above-discussed belief in the individual, means that any active forum member becomes a potential spokesperson or representative of the movement. At least in theory. This can also be interpreted as another way of handling the complexity of representation as a movement intellectual. Because still, in some contexts, the culture of online piracy is described as being very hierarchical and elitist, and is said to exclude people by using complicated technological jargon and codes that are impossible for newcomers or outsiders to understand (Cooper \& Harrison 2001, p. 72). The fact that the organized part of the movement in Sweden seems to be largely male dominated is another aspect of this. It can be hard for new or aspiring members of the community to find their place. But at least to those that are already in, places on the internet such as chats and forums play an important role in fostering the common conscience of the movement.

The Technological Dimension and the Actions The technological dimension revolves around the performance techniques of activists and the actions taken to convey cognitive praxis. In the online piracy movement, technology and technological development are crucial elements. As we will show in the next section, this movement's cosmological dimensions - it's "utopian messages" - are based on ideas of individual freedom and autonomy. The technological dimensions of the cognitive praxis are tightly knit to these cosmological dimensions.

The most prominent political action related to online piracy is of course to contribute, by uploading and downloading, to the free flow of culture and information. But according to discussions outlined earlier, there is no need for these "activists" to share any collective sense of identity, since what makes the potential movement what it is, is actually the aggregate number of online piracy acts.

Even if the everyday practice of actually sharing files is a political action of central importance in itself, other actions are also of significance to the dissemination of ideas and knowledge related to online piracy. Some of these actions are similar to the performance techniques of earlier social movements. For example $T B P$ and $P P$ have arranged a number of direct demonstrations and petitions. Rallies set up on the International Workers' Day (May 1st) can be seen as a way to position the ideas within a social movement heritage, but in this case it was also claimed by 
the pirate demonstrators that the demands of the workers movement are obsolete. Today we must, TBP stated in a text published on different internet forums in connection to the demonstration, shift the focus of attention towards issues of internet access and free information as basic human rights.

The Internet has become a fundamental prerequisite for both work and entertainment - a basic human right like having food for the day or fresh air to breathe. But the access is just as unequally distributed as that to schools or medical services was a hundred years ago.

The use of traditional forms of activism - or 'survivings' in Eyerman and Jamison's terminology - in the online piracy movement can be interpreted as a way to draw legitimate attention to the cosmological dimensions, by making use of methods historically affiliated with previous social movements. These performance techniques, however, are not the main forms of subpolitical practice in the online piracy movement. The fact that the actions are mainly based in an online environment and can be built around different networks and projects indicates that the flexibility and dynamics characterizing the technology, fundamental for the existence of the movement, is also embedded in new forms of political participation.

Because of the digitalized and computerized nature of online piracy, it is tempting to believe that this particular movement will have a different relation to technology than most of its predecessors. But if we, just as an example, compare it to the environmental movement, one instead finds noticeable similarities between the two. Just as the environmental movement has worked consciously on the development of alternative, environmentally friendly technologies (Eyerman \& Jamison 1991), many file sharers also express ideas about how alternative digital technologies can make the world a better place. For instance, TBP has encouraged and lobbied for the setting up of open access wireless networks in as many places as possible all over Sweden.

So, in the case of the environmental movement, for example, technology is used to achieve lifestyles and societies that are ecologically sustainable. In the case of online piracy, technology is employed to reach or promote certain goals within the sphere of arts, cultural policy and the dissemination of information and ideas in general. In both cases however, technology plays a crucial role in the process, described by Melucci (1989) wherein "means" and "goals" are brought together to form the basis of what he labels "new social movements".

In the eyes of the advocates of online piracy, technology used in the right way can work as a tool for decentralizing power. Technology can help the individual resist large-scale industry. The similarities with the Open Source and Free Software movements promoting software in which the source code is freely available for others to view, amend, and adapt (DiBona m.fl. 1999; Stallman 2002), as well as the so called DiY-cultures focusing on people creating things themselves without the aid of paid professionals (McKay 1998), are obvious here. These are all movements where the very use of certain technologies becomes a political action that can give a feeling of freedom and autonomy. This is further illustrated by the fact that the restraint of culture in this context can be perceived as an attack on the dignity of the individual: "Pirates are horrified when their connectivity and resources get blocked" (Cooper \& Harrison 2001, p. 86).

In other words, the advocates of online piracy strive to create a historical project of their own by relating both to history and the future. The way in which they act offensively, rather than defensively (for example, TBP's choice of name), and use humor and symbolism as rhetorical tools are examples of this. In the late 1970s, home taping was given the blame for the crisis within the record industry. This lead to the "Home taping is killing music (and it's illegal)"-campaign in the early eighties, with the cassette shaped skull and crossbones logo. The contemporaneous copying movement answered by hijacking the symbol of their antagonists, but instead using the slogan of "Home taping is killing business (and it's easy)". This took place in an era when the cognitive praxis of today's online piracy movement began to take shape. The cassette skull is now the logotype of TBP, and it is also employed by other actors in its surroundings. All of this contributes to the construction of collective identity by referring to a common history and symbolism.

The Cosmological Dimension

The cosmological dimension, lastly, revolves around the utopian messages that the movement stands for, what it is that needs to be "overcome or transcended" (Eyerman \& Jamison 1998, p. 167). Despite the fact that the movement is ideologically fragmented and heterogeneous, we will argue that there are in fact a set of common denominators.

We can for example identify an interesting parallel between the social and the technological elements of online piracy. The most prominent ideas in the cosmological dimension are the decentralization of power and control, and anti-authoritarianism. These two themes put their mark, not only on the interpersonal social relations, but also on the technological side of things. For instance, one of the representatives of TBP claims that, to him, online piracy is first and foremost about technology and its possibilities. In the light of such an assertion, it becomes meaningful to describe the cosmological dimension of online piracy in terms similar to those applied to the hardware of peer-to-peer networks, which are by definition decentralized in their actual infrastructure (Vaidhyanathan 2004, p. 17). This is similar to the ethics of "openness, peer review, individual autonomy and communal responsibility" (ibid, p. 39), expressed within the preceding hacker culture, the main focus of which is to obtain unauthorized access to various systems through specialist knowledge, skills and tactics. It also has a clear relation to Castells' (2001) description of an "internet culture" imbued with these ideals and agencies.

Another important aspect of the cosmological dimension is related to the idea that free access to culture and information are basic human rights. The kind of critique of copyright supported by $T B P$ is not only about mp3-files or ripped DVD's, but many other things such as, for example, the lack of patented and legitimate medications in some developing countries. Magnus from $T B P$ stated: "Partly, we want to broaden the debate to include, maybe, censorship and arts or medical patents and things like that, and connect all of those things. A horizontal widening, you could say, of the debate."

Another key cosmological aspect appearing throughout the material is the criticism of large-scale companies and institutions that use their power to prevent the free flow of culture and information strived for by the online pirates. Magnus from TBP said that: "A world where, like, the companies own any ideas or creativity, that's a very boring world". This indicates that the informant is against companies owning everything, however it says nothing about what ideas or creativity he feels it is reasonable that companies are allowed to own. The idea of 
ownership, then, seems to be interpreted in a very broad sense, bordering on over-generalization. Similarly, both representatives from $T B P$, express rather inexact ideas about "individual freedom". In fact, it is not always obvious if one should read their argumentation in terms of a radical critique of neo-liberal capitalism, or as being in defense of such values of "autonomy" or "freedom of choice" that actually are common parts of neo-liberal ideology. On the other hand there is a rather neo-liberal idea that what is good for the individual will also be good for others. One of the interviewed representatives from $T B P$ said:

It is a kind of egoism that has to include other people, sort of. [...] For me to be satisfied, other people around me need to be satisfied too. So, I guess that's the basis of the file sharing movement, maybe. [...] Not built on an idea that man has to be in solidarity with others to be good. And like, "you ought to be like this, for moral reasons, and therefore we should". If we show solidarity towards one another, then it gets better for everyone, kind of. A very primal view of solidarity, you could say.

This idea might be seen as a form of "egoistic solidarity" which is further emphasized in a number of media appearances by $T B P$, in which it expresses the belief that the film and music industries need to adjust to people's choices in the field of cultural consumption, rather than dictate the conditions from above. In sum, there is an ambiguity here: While the cosmology of online piracy has some apparently neo-liberal aspects, it is at the same time characterized by the refusal to respect the laws of commodification whereby knowledge and information is turned into goods that can be bought and sold. Online piracy networks can, of course, potentially be used for both politically conservative and radical ends. This may again indicate that the phenomenon defies easy categorization along a left-right scale, and/or simply that online pirates are, again, a politically heterogeneous group. To many previous social movements, unity and solidarity within the group has played a crucial role. As we have touched upon many times in this paper, online piracy is clearly more ideologically fragmented and individualistic. This issue is also brought forward by our informants from TBP:

I can find reasons both for and against file sharing from leftwing as well as right-wing perspectives. I mean, arguments from the left can defend piracy by relating to democracy issues about the importance of everyone getting free access [to information and culture], but they can also be against piracy in order to protect the rights of cultural workers. And on the right-wing side it can, of course, be about protecting the companies, but also about personal freedom and things like that.

This rather vague answer can also be interpreted as a strategy for a person to, in his role as a movement intellectual, handle the movements' ideological and cosmological differentiation in an inclusive way.

In sum, we have identified different online piracy cultures and shown how these cultures in different ways can be related to various levels of activism, such as subactivism and subpolitics. We have analyzed the cognitive praxis of the online piracy movement and argued that it is ideologically diffuse but permeated by the idea of a shift from the collective to the individual domain, and by the highlighting of technology. These latter two aspects are steadily present throughout all of its dimensions.
CHANGES IN POLITICAL ACTIVISM?

Eyerman and Jamison argue that "the collective identity formation that takes place in social movements is a central catalyst of broader changes in values, ideas, and ways of life" (1998, p. 7). In times of change, social movements act as driving forces as well as emergency brakes. The workers' movement in the 19th century was a response to certain social transformations. It represented the first wave of modern social movements. The second wave came as a response to post-war societal transformation. It spawned branches such as the feminist, civil rights and environmental movements. Applying this contextual way of looking at social movements one could ask, what characterizes the social movements that are emerging at our present space in time? What can be said about the forms of counter cultural activism and political participation that are taking place forty years after 1968, when the second wave of movements have culminated? Are we witnessing a third wave of collective activism, of which the online piracy movement is an example? And - if so - what distinguishes it from, or unites it with, those of previous eras?

As we have shown in the previous section, the act of online piracy can indeed be understood in terms of Eyerman and Jamison's perspective on the cognitive praxis of social movements. This, then, also indicates that online piracy can in some sense be recognized as a social movement, at least in the Swedish case described here.

Within the Swedish online piracy movement, we have identified a reluctance when it comes to talking of common visions or ideologies. We have also discussed the difficulties in categorizing online piracy as belonging to either the political left or right in a traditional sense. However, we argue that this fragmented approach and shift from the collective to the individual domain is itself, in fact, an indication of a common idea - or cognitive praxis - and therefore something more than a mere aggregation of individual behaviors that just happen to coincide.

Additionally, most of the activities organized by TBP would be impossible to even carry out without some sort of collective identity or cognitive praxis. With no solidarity within the group it would also be difficult to use any common symbols or language to connect to a shared history or to identify a common opponent. But these are, however, all activities that are constantly carried out within the movement discussed in this paper.

The fact that the online piracy movement is so looseknit and heterogeneous is certainly symptomatic of our times. Eyerman and Jamison (2005, p. 208) claim that today's society is so multifaceted that it is not fruitful at all to speak of actual movements. The activism of today is described as too "limited and part time" to be seen as examples of new waves of political opposition. Still, from their contextual perspective, it is easy to see how the online piracy movement springs from noticeable contextual factors at the social and cultural levels - for example such factors summarized by Castells (2001, pp. 36-61) as "the culture of the Internet".

This is a culture described in terms of four layers: techno-meritocratic culture, hacker culture, the virtual communitarian culture, and entrepreneurial culture. The first layer is inhabited by a techno-elite with a strong belief in the inherent good of technological development for the progress of society. Among these groups, merit is rewarded for contributing to the advancement of the system of networked computers that grows exponentially. As Castells (2001, p. 40) puts it: 'The cornerstone of the whole process is the open communication of software". 
The second layer is composed of hackers with a similar goal of performance, and a common need for sharing and for keeping source codes open. Aside from these two groups of technological innovators, the third layer is populated by virtual communitarians forming communities that give rise to forms of online social organization characterized by "horizontal, free communication" (Castells 2001, p. 54). The fourth and final layer is made up of entrepreneurs who are forerunners in a transformation process towards a new economy marked by new rules of production, calculation, and circulation.

It is quite easy to see how the technologically driven and economically disruptive activity of online piracy, which is clearly based on principles of contribution, networking, and free, horizontal communication of source code, fits into this context. However, it is also important to emphasize the one-dimensional aspects of Castells argument. It might be more fruitful to speak of "cultures of the Internet" in the plural form. Furthermore, the movement has its basis in an existence which is becoming more and more individualistic and technologisized. Even though the activism of today may seem to be "limited and part time", the fact is that much of today's protest is carried out on a more than full time basis. This is because activism of the third wave is so large a part of lived everyday practice. It is obvious in the example of the online piracy movement that, for example, traditional demonstrations and rallies are not the main communicative context.

All of the activities taking place within the loosely knit network of the Swedish online piracy movement can be seen as examples of how subpolitical participation, innovation and social movements come into being at the beginning of the $21^{\text {st }}$ century. By analyzing the online piracy movement, one therefore gains a certain insight into how these things work in more general terms in our present day and age. In fact, it is debatable whether coexisting social movements can be understood separately at all. In general, the third wave of social movements taking shape today is marked by an emphasis on the interaction between the individual and technology. This is obvious in the online piracy movement as well as in the Open Source movement, and in the new wave of citizen journalism (Gillmor, 2006; Klein, 1999) or the participatory cultures described by the likes of Jenkins (2006a; 2006b). The very use of contemporary technologies can in these cases contribute to feelings of freedom, autonomy and participation.

In order to understand new forms of political activism, it is important to analyze the social movements of the $21^{\text {st }}$ century, even though they are loosely held together and in spite of the fact that it is always easier to discuss things in hindsight. Claiming that the advent of digital technology automatically leads to ground-breaking and amazing possibilities for people to make their voice heard would be to oversimplify things. It is of course more complicated than that. Not only because there are significant class-based, gendered and generational differences as regards the access to - and the knowledge of how to operate - digital media. But also since these participatory tools are often used in unexpected and innovative ways. Such resourcefulness and creativity come about for a number of reasons that undeniably demand further investigation if we are to better understand contemporary as well as future forms of political involvement. 


\section{WORKS CITED}

Bakardjieva, M., 2009. Subactivism: Lifeworld and Politics in the Age of the Internet. The Information Society, 25.

Beck, U., 1997. The reinvention of politics: Rethinking modernity in the global social order, Cambridge, UK: Polity.

Bowrey, K., 2005. Law and internet cultures, Cambridge, UK: Cambridge University Press.

Castells, M., 1975. La question urbaine. Paris: Maspero.

Castells, M., 1996. The information age: Economy, society and culture. Vol. 1: The Rise of The Network Society, Oxford: Blackwell.

Castells, M., 2001. The internet galaxy: Reflections on the Internet, business, and society, Oxford: Oxford University Press.

Cooper, J. \& Harrison, D.M., 2001. The social organization of audio piracy on the Internet. Media, Culture and Society, 23(1).

Dahlgren, P., 2007. Civic identity and net activism: The frame of radical democracy. Dahlgren, P. \& Siapera, E (eds) Radical democray and the Internet. London: Palgrave Macmillan.

della Porta, D., \& Dani, M., 2006. Social movements: An introduction. Oxford: Blackwell.

DiBona, C., Ockman, S. \& Stone, M., 1999. Open sources voices from the open source revolution, London: O'Reilly.

Eyerman, R. \& Jamison, A., 1991. Social movements: A cognitive approach, University Park, $\mathrm{Pa}$ : Pennsylvania State University Press.

Eyerman, R. \& Jamison, A., 1998. Music and social movements: Mobilizing traditions in the twentieth century, Cambridge, UK: Cambridge University Press.

Eyerman, R. \& Jamison, A., 2005. Sociala rörelser $i$ en ny tid, Lund: Studentlitteratur.

Fattah, H.M., 2002. P2P: How peer-to-peer technology is revolutionizing the way we do business, Chicago, IL: Dearborn Trade Pub.

Findahl, 0., 2009. Svenskarna och Internet 2009. Gävle: World Internet Institute.

Gantz, J. \& Rochester, J.B., 2005. Pirates of the digital millennium: How the intellectual property wars damage our personal freedoms, our jobs, and the world's economy, Upper Saddle River, NJ: Prentice Hall/Financial Times

Giesler, M. \& Pohlmann, M., 2003. The Social Form of Napster: Cultivating the Paradox of Consumer Emancipation. Advances in Consumer Research, $30(1)$

Gillmor, D., 2006. We the media: Grassroots journalism by the people, for the people, Beijing: 0'Reilly.

Gordon, S. M., (2005). Downloading copyrighted stuff from the Internet: Stealing or fair use? Berkeley Heights, NJ: Enslow Publishers.

Gummadi, K.P. m.fl., 2003. Measurement, modeling, and analysis of a peer-to-peer file-sharing workload. Proceedings of the nineteenth ACM symposium on operating systems principles.

Gupta, P.B., Gould, S.J. \& Pola, B., 2004. 'To Pirate or Not to Pirate': A comparative study of the ethical versus other influences on the consumer's software acquisition-mode decision. Journal of Business Ethics, $55(3)$.

Hinduja, S., 2003. Trends and patterns among online software pirates. Ethics and Information Technology, $5(1)$

Jenkins, H., 2006a. Convergence culture: Where old and new media collide, New York: New York University Press.

Jenkins, H., 2006b. Fans, bloggers, and gamers: exploring participatory culture, New York: New York University Press.
Kaarto, M., \& Fleischer, R. (Eds.). (2005). Copy Me. Collected texts from The Bureau of Piracy. Stockholm: Roh-Nin.

Klein, H.K., 1999. Tocqueville in Cyberspace: Using the Internet for Citizen Associations. The Information Society, 15(4).

Klein, N., 2000. No logo: taking aim at the brand bullies, London: Flamingo.

Lévy, P., 1999. Collective intelligence: Mankind's emerging world in cyberspace, Cambridge, Mass.: Perseus Books.

Leyshon, A. m.fl., 2005. On the reproduction of the musical economy after the Internet. Media, Culture \& Society, $27(2)$.

Linde, J., 2005. "Sharing is caring”. Om Piratbyrån och kognitiv praxis i en ny social rörelse. Växjö University.

Lindgren, S., 2007. From Flâneur to Web Surfer: Videoblogging, Photo Sharing and Walter Benjamin @ the Web 2.0. Transformations, 2007(15). Available at:

http://www.transformationsjournal.org/journal/iss ue_15/article_10.shtml.

Lindgren, S., 2009. Unga fildelningskulturer. Lindgren, S. (ed), Ungdomskulturer. Malmö: Gleerups.

Logsdon, J.M., Thompson, J.K. \& Reid, R.A., 1994. Software piracy: Is it related to level of moral judgment? Journal of Business Ethics, 13(11).

Luke, T.W., 1989. Screens of power: Ideology, domination, and resistance in informational society, Urbana: University of Illinois Press.

Lunney, G.S., 2001. The death of copyright: Digital technology, private copying, and the digital millennium copyright act. Virginia Law Review, 87(5).

Mason, M., 2008. The pirate's dilemma: How youth culture reinvented capitalism, New York: Free Press.

McCaughey, M. \& Ayers, M.D., 2003. Cyberactivism: online activism in theory and practice, New York: Routledge.

McKay, G., 1998. DiY culture: party and protest in nineties' Britain, London: Verso.

McLeod, K., 2005. Freedom of expression $₫$ : overzealous copyright bozos and other enemies of creativity, New York: Doubleday.

Melucci, A. (1989). Nomads of the present: Social movements and individual needs in contemporary society. London: Raduis.

Murray, B. H. (2003). Defending the brand: Aggressive strategies for protecting your brand in the online arena. New York: American Management Association.

Miles, I., 1988. Information horizons: The long-term social implications of new information technologies, Aldershot: E. Elgar.

Oberholzer-Gee, F., \& Strumpf, K. (2007). The effect of file sharing on record sales: An empirical analysis. Journal of political economy, 115(1)

Rheingold, H., 2002. Smart Mobs: The Next Socia Revolution, Cambridge, Mass.: Perseus

Ripeanu, M. \& Foster, I., 2002. Mapping the Gnutella network: Macroscopic properties of large-scale peerto-peer systems. Peer-To-Peer Systems: First International Workshop, IPTPS 2002, Cambridge, MA, USA, March 7-8, 2002: Revised Papers.

Rojek, C., 2005. Leisure theory: Principles and Practice. London: Palgrave Macmillan.

Rydell, A. \& Sundberg, S., 2009. Piraterna: De svenska fildelarna som plundrade Hollywood, Ordfront.

Schmidt, A. H. J. (2007). Fighting the war on file sharing. The Hague: T.M.C Asser.

Stallman, R.M., 2002. Free software, free society: selected essays of Richard M. Stallman, Boston, Mass.: GNU Press. 
Strangelove, M., 2005. The empire of mind: Digital piracy and the anti-capitalist movement, Toronto: University of Toronto Press.

Sum, N.L., 2003. Informational capitalism and US economic hegemony: Resistance and adaptations in East Asia. Critical Asian Studies, 35(3).

Summers, C. \& Markusen, E., 1992. Computers, ethics, and collective violence. Journal of Systems and Software, 17(1).

Swinyard, W.R., Rinne, H. \& Kau, A.K., 1990. The morality of software piracy: A cross-cultural analysis. Journal of Business Ethics, 9(8).

Söderberg, J. (2008). Allt mitt är ditt: fildelning, upphovsrätt och försörjning. Stockholm: Atlas.

Turkle, S., 1995. Life on the screen: Identity in the age of the Internet, New York: Simon \& Schuster.
Vaidhyanathan, S., 2004. The anarchist in the library: How the clash between freedom and control is hacking the real world and crashing the system, New York: Basic Books.

Wettergren, Å., 2005. Moving and jamming: implications for Social Movement Theory, Karlstad: Department of Sociology, Division for Social Sciences, Karlstad University.

Wright, G., 2008. P2P Next, Available at: http://www.bbc.co.uk/blogs/bbcinternet/2008/02 /p2p_next.html.

Yar, M., 2005. The global 'epidemic' of movie 'piracy': Crime-wave or social construction? Media, Culture \& Society, 27(5). 